\title{
A NUMERICAL METHOD FOR INVERSE SPECTRAL PROBLEMS
}

S.I.Kadchenko, Magnitogorsk State Technical University named after G.I. Nosov, Magnitogorsk, Russian Federation, kadchenko@masu.ru, G.A. Zakirova, South Ural State University, Chelyabinsk, Russian Federation, zakirova81@masu.ru

Basing on the Galerkin methods, we develop a new numerical method for solving the inverse spectral problems generated by discrete lower semibounded operators. The restrictions on the perturbing operator are relaxed in comparison with the method based on the theory of regular traces. A Fredholm integral equation of the first kind enables us to recover the values of the perturbing operator at the discretization nodes. We tested the method on spectral problems for the Sturm - Liouville operator, and the results of numerous simulations demonstrate its computational efficiency.

We found simple formulas for the eigenvalues of a discrete lower semibounded operator avoiding the roots of the corresponding secular equations. The calculation of eigenvalues of these operators can start at an arbitrary index independently of the (un)availability of the eigenvalues with smaller indices. For perturbed selfadjoint operators we can calculate eigenvalues with large indices when the Galerkin method becomes difficult to apply.

Keywords: inverse spectral problem; discrete selfadjoint operators; eigenvalues; eigenfunctions; ill-posed problems.

\section{Introduction}

The inverse problems of spectral analysis amount to reconstructing differential operators given certain spectral characteristics. They are important in various branches of mathematics and have many applications in mechanics, physics, electronics, geophysics, metrology, seismology, identification of composites, and other fields of natural sciences and technology. The interest in this topic grows constantly as new inverse spectral problems describing complicated technical processes arise. Presently, the theory of inverse spectral problems is actively developing in all leading countries of the world.

The most thorough studies in the theory of inverse problems deal with the Sturm - Liouville differential operator

$$
l y \equiv-y^{\prime \prime}+q(x) y
$$

The first works on the Sturm - Liouville inverse spectral problem include Ambarzumian's article [1]. He proved that for the eigenvalues $\lambda_{k}=k^{2}$ with $k \geq 0$ the potential $q$ must vanish identically. It turned out subsequently that this result is special and in general the spectrum alone is insufficient for reconstructing $q$ uniquely. Borg proved [2] that two spectra of the Sturm - Liouville operator with the same boundary conditions uniquely determine the function $q$. Marchenko proved [3] that the Sturm - Liouville differential operator defined on the semiaxis or a finite interval is uniquely determined by the spectral function. For a finite interval this corresponds to specifying the spectral data. While solving the problem of determining the density of an inhomogeneous symmetric string given its frequency spectrum, Krein showed [4] that a symmetric potential is always uniquely determined by the frequency spectrum. 
Making no attempt at surveying all research directions and the numerical methods developed to solve inverse spectral problems, we mention the articles relying on the method of regular traces. The advantage of this method is its applicability to both ordinary and partial differential operators. Sadovnichii and Dubrovskii published the first article in this direction [5]. They proved the existence and uniqueness of solutions to the inverse spectral problems for selfadjoint semibounded discrete operators acting on separable Hilbert spaces and established the possibility of reconstructing the perturbing operator from the spectrum of the operator alone provided that it is "small". Dubrovskii and Nagornyi gave [6,7] the first theoretical justification to the application of the method of regular traces to inverse spectral problems for the perturbed Laplace operator. The theory of inverse problems for the Laplace operator with potential was further advanced in the work of Sadovnichii, Dubrovskii, and their school [8, 17]. Algorithms to solve approximately the inverse spectral problems generated by a perturbed power of the Laplace operator were developed in [18].

The method of $[19,22]$ enables us to solve the inverse spectral problems generated by discrete lower semibounded operators. Let us recall its main idea. Take a discrete lower semibounded operator $T$ and a bounded operator $P$ on a separable Hilbert space $H$. Assume that the eigenvalues $\left\{\lambda_{n}\right\}_{n=1}^{\infty}$ and orthonormal eigenfunctions $\left\{v_{n}\right\}_{n=1}^{\infty}$ of $T$ are available and enumerate them in the ascending order of $\lambda_{n}$, taking their multiplicities $\nu_{n}$ into account. Denote by $n_{0}$ the number of distinct eigenvalues $\lambda_{n}$ lying inside the circle $T_{n_{0}}$ of radius $\rho_{n_{0}}=\frac{\left|\lambda_{n_{0}+1}+\lambda_{n_{0}}\right|}{2}$ centered at the origin. Enumerate as $\left\{\mu_{n}\right\}_{n=1}^{\infty}$ the eigenvalues of the operator $T+P$ in the ascending order of their real parts, taking into account their algebraic multiplicities.

If $q_{n}=\frac{2\|P\|}{\left|\lambda_{n+\nu_{n}}-\lambda_{n}\right|}<1$ for all $n \in N$ and the system of eigenfunctions $\left\{v_{n}\right\}_{n=1}^{\infty}$ of $T$ constitutes an orthonormal basis of $H$ then $m_{0}=\sum_{n=1}^{n_{0}} \nu_{n}$ and we can calculate the eigenvalues $\left\{\mu_{n}\right\}_{n=1}^{m_{0}}$ of $T+P$ as

$$
\mu_{n}=\lambda_{n}+\left(P v_{n}, v_{n}\right)+\widetilde{\delta}(n), n=\overline{1, m_{0}}
$$

where $\widetilde{\delta}(n)=\delta(n)-\delta(n-1)$ with $\delta(n)=\sum_{k=1}^{n}\left[\mu_{k}-\widetilde{\mu}_{k}(n)\right]$ and $\widetilde{\mu}_{k}(n)$ is the $n$th Galerkin approximation to the corresponding eigenvalue $\mu_{k}$ of $T+P$. For $\widetilde{\delta}(n)$ we have the estimates

$$
|\widetilde{\delta}(n)| \leq(2 n-1) \rho_{n} \frac{q^{2}}{1-q}, \quad q=\max _{n \in N} q_{n} .
$$

In the case that $P$ is the operator of multiplication by a function $p(s)$, we can use (1) to construct the Fredholm integral equation of the first kind

$$
\int_{a}^{b} K(x, s) p(s) d s=f(x), c \leq x \leq d
$$

where the functions $f(x)$ and $K(x, s)$ satisfy

$$
f\left(x_{k}\right)=\widetilde{\mu}_{k}-\lambda_{k}+\sum_{k=1}^{n-1}\left[\widetilde{\mu}_{k}(n)-\widetilde{\mu}_{k}(n-1)\right], \quad K\left(x_{k}, s\right)=v_{k}^{2}(s), c \leq x_{k} \leq d, k=\overline{1, n} .
$$

If the kernel $K(x, s)$ is continuous and closed in the rectangle $\Pi=[a, b] \times[c, d]$, while $p(s) \in W_{2}^{1}[a, b]$ and $f(x) \in L_{2}[c, d]$, then the integral equation has a unique solution, which determines the values of $p$ at the discretization nodes of the interval $[a, b]$.

Since we obtained (1) under the restriction $\|P\|<0,5\left|\lambda_{n+\nu_{n}}-\lambda_{n}\right|$ for all $n \in N$, it became necessary to construct a numerical method with relaxed restrictions on the perturbing operator $P$, which is done in this article. 


\section{Finding the Eigenvalues of Discrete Lower Semibounded Operators with a Modified Galerkin Method}

Consider a discrete lower semibounded operator $L$ on a separable Hilbert space $H$. We determine the eigenvalues $\mu$ by finding the nontrivial solutions to the equation

$$
L u=\mu u
$$

satisfying certain homogeneous boundary conditions.

To find the eigenvalues of $L$, we use the Galerkin method. Introduce a sequence $\left\{H_{n}\right\}_{n=1}^{\infty}$ of finite-dimensional spaces $H_{n} \subseteq H$ which is complete $H$. Assume available an orthonormal basis for $H_{n}$ consisting of some functions $\left\{\varphi_{k}\right\}_{k=1}^{n}$ satisfying all boundary conditions of the problem. Following the Galerkin method, we seek an approximate solution to the spectral problem (2) in the form

$$
u_{n}=\sum_{k=1}^{n} a_{k}(n) \varphi_{k}
$$

Theorem 1. Consider a discrete lower semibounded operator $L$ on a separable Hilbert space $H$. If the system of coordinate functions $\left\{\varphi_{k}\right\}_{k=1}^{\infty}$ constitutes a basis for $H$ then the Galerkin method constructed from this system of functions and applied to the problem of finding the eigenvalues of the spectral problem (2) converges.

Доказательство. Express (2) as

$$
(L-\lambda E) \varphi=(\mu-\lambda) \varphi .
$$

The discrete operator $L$ admits the resolvent $R_{\lambda}(L)=(L-\lambda E)^{-1}$, which is compact in $H$. Acting by $R_{\lambda}(L)$ from the left on both sides of $(3)$, we obtain

$$
\varphi=(\mu-\lambda) R_{\lambda}(L) \varphi
$$

Basing on [23], the Galerkin method applied to the problem of finding the eigenvalues of (4), and so of (2) as well, converges.

Theorem 2. Consider a discrete lower semibounded operator $L$ acting on a separable Hilbert space $H$. If the system of coordinate functions $\left\{\varphi_{k}\right\}_{k=1}^{\infty}$ constitutes an orthonormal basis for $H$ then

$$
\widetilde{\mu}_{n}(n)=\left(L \varphi_{n}, \varphi_{n}\right)+\delta_{n},
$$

where $\delta_{n}=\sum_{k=1}^{n-1}\left[\widetilde{\mu}_{k}(n-1)-\widetilde{\mu}_{k}(n)\right]$ and $\widetilde{\mu}_{k}(n)$ is the nth Galerkin approximation to the corresponding eigenvalue $\mu_{k}$ of $L$.

Доказательство. Inserting (3) into (2) yields

$$
\sum_{k=1}^{n} a_{k}(n) L \varphi_{k}=\widetilde{\mu}(n) \sum_{k=1}^{n} a_{k}(n) \varphi_{k} .
$$

The coefficients $\left\{a_{k}(n)\right\}_{k=1}^{n}$ are determined from the requirement that the left-hand side here be orthogonal to the functions $\left\{\varphi_{l}\right\}_{l=1}^{n}$, which leads to the system of linear equations

$$
\sum_{k=1}^{n} a_{k}(n)\left\{\widetilde{\mu}(n) \delta_{k, l}-\left(L \varphi_{k}, \varphi_{l}\right)\right\}=0, l=\overline{1, n}
$$


on the coefficients $\left\{a_{k}(n)\right\}_{k=1}^{n}$, where $\delta_{k, l}$ is the Kronecker symbol. Setting its determinant equal to zero, we arrive at the equation

$$
\operatorname{det}(\mathbf{A}-\widetilde{\mu}(n) \mathbf{E})=0
$$

which defines the approximate values of the first $n$ eigenvalues $\left\{\widetilde{\mu}_{k}(n)\right\}_{k=1}^{n}$ of $L$. Here $\mathbf{E}$ is the $n \times n$ identity matrix and $\mathbf{A}=\left(a_{k l}\right)_{k, l=1}^{n}$ is the $n \times n$ matrix with $a_{k l}=\left(L \varphi_{k}, \varphi_{l}\right)$.

It is known [24] that the eigenvalues $\left\{\widetilde{\mu}_{k}(n)\right\}_{k=1}^{n}$ of $\mathbf{A}$ satisfy

$$
\sum_{k=1}^{n} \widetilde{\mu}_{k}(n)=S p \mathbf{A}
$$

which yields

$$
\sum_{k=1}^{n} \widetilde{\mu}_{k}(n)=\sum_{k=1}^{n} a_{k k}
$$

Introducing $\mu_{k}=\widetilde{\mu}_{k}(n)+\varepsilon_{k}(n)$, we have

$$
\sum_{k=1}^{n} \mu_{k}=\sum_{k=1}^{n}\left[a_{k k}+\varepsilon_{k}(n)\right]
$$

Subtracting (6) for $n-1$, namely,

$$
\sum_{k=1}^{n-1} \mu_{k}=\sum_{k=1}^{n-1}\left[a_{k k}+\varepsilon_{k}(n-1)\right]
$$

from (7), we infer that

$$
\mu_{n}=\left(L \varphi_{n}, \varphi_{n}\right)+\mu_{n}-\widetilde{\mu}_{n}(n)-\sum_{k=1}^{n-1}\left[\widetilde{\mu}_{k}(n)-\widetilde{\mu}_{k}(n-1)\right]
$$

or

$$
\widetilde{\mu}_{n}(n)=\left(L \varphi_{n}, \varphi_{n}\right)+\sum_{k=1}^{n-1}\left[\widetilde{\mu}_{k}(n-1)-\widetilde{\mu}_{k}(n)\right] .
$$

This justifies the theorem.

Based on the Galerkin method, (5) enables us to find approximate eigenvalues of discrete lower semibounded operators and uses only the scalar products $\left(L \varphi_{n}, \varphi_{n}\right)$. This considerably improves computational efficiency in comparison with the classical Galerkin method.

Observe that to obtain (5) we used the diagonal elements $a_{k k}=\left(L \varphi_{k}, \varphi_{k}\right)$ for $k=\overline{1, n}$ of the square matrix $\mathbf{A}=\left(a_{k l}\right)_{k, l=1}^{n}$. For small $n$ the error of finding the eigenvalues $\left\{\widetilde{\mu}_{k}\right\}_{k=1}^{n}$ can be significant; consequently, we should apply (5) with care. If the requirements of Theorem 1 are fulfilled then the Galerkin method converges; therefore, as $n$ grows, the calculation of $\widetilde{\mu}_{n}$ using (5) becomes more accurate. In addition, we can calculate the approximate eigenvalues $\widetilde{\mu}_{n}$ of $L$ using (5) starting at an arbitrary desired index $n$ since the values with smaller indices are avoided. 


\section{Solutions of Inverse Spectral Problems Generated by Perturbed Selfadjoint Operators}

Assume that the operator $L$ of $(2)$ is of the form

$$
L=T+P,
$$

where $T$ is a selfadjoint operator and $P$ is the bounded operator of multiplication by a function $p(s)$ of $s \in[a, b]$ on the separable Hilbert space $L_{2}[a, b]$. Consider the problem of reconstructing the potential $P$ from the eigenvalues $\left\{\mu_{k}\right\}_{k=1}^{n}$ of the operator $T+P$ on $L_{2}[a, b]$.

Use (5) to construct the Fredholm integral equation of the first kind

$$
\int_{a}^{b} K(x, s) p(s) d s=f(x), c \leq x \leq d,
$$

where the functions $f(x)$ and $K(x, s)$ satisfy

$$
f\left(x_{k}\right)=\widetilde{\mu}_{k}-\int_{a}^{b} T\left(\varphi_{k}(s)\right) \varphi_{k}(s) d s-\delta_{k}, \quad K\left(x_{k}, s\right)=\varphi_{k}^{2}(s), c \leq x_{k} \leq d, k=\overline{1, n} .
$$

If the kernel $K(x, s)$ of $(9)$ is continuous and closed in the rectangle $\Pi=[a, b] \times[c, d]$, while $p(s) \in W_{2}^{1}[a, b]$ and $f(x) \in L_{2}[c, d]$, then the solution to (9) is unique [25]. By the definition of $f(x)$, its values at the points $x_{k}$ are known approximately. Denote by $\widetilde{f}\left(x_{k}\right)$ the approximate values to $f\left(x_{k}\right)$ satisfying $\left\|f\left(x_{k}\right)-\widetilde{f}\left(x_{k}\right)\right\| \leq \xi$ for all $x_{k} \in[c, d]$. This estimate is useful in our construction of a numerical algorithm to solve this problem.

To find a solution of the Fredholm integral equation of the first kind (9) is an ill-posed problem, but Tikhonov's regularization method yields an approximate solution $\widetilde{p}(s)$. The numerical solution of (9) will determine the approximate values $\widetilde{p}(s)$ of $p(s)$ at the nodes $s_{i}$ for $i=\overline{1, I}$, with $a=s_{1}<s_{2}<\ldots<s_{I}=b$. To achieve good accuracy of interpolation for $\widetilde{p}(s)$, we can choose a sufficiently large number $I$ of nodes.

Choose the interval $[c, d]$ so that we can find the eigenvalues $\widetilde{\mu}_{n}$ in it using (5) with the required accuracy.

Thus, using (5), we construct the integral equation (9) whose solution enables us to find the approximate values $\widetilde{p}(s)$ of the operator $p(s)$ at the discretization nodes $s_{i}$ of the interval $[a, b]$.

\section{Numerical Experiments}

We applied our method to solve the spectral problem

$$
\left\{\begin{array}{l}
L u \equiv-u^{\prime \prime}+p(s) u=\mu u, \quad a<s<b ; \\
\cos \alpha u^{\prime}(a)+\sin \alpha u(a)=0 ; \\
\cos \gamma u^{\prime}(b)+\sin \gamma u(b)=0, \quad \alpha, \gamma \in[0,2 \pi] .
\end{array}\right.
$$

Assume that the approximate eigenvalues $\widetilde{\mu}$ of $L$ are available. Using them, reconstruct the approximate values $\widetilde{p}(s)$ of the potential $p(s)$ at the discretization nodes $s_{k}$ of the interval $[a, b]$.

To construct an orthonormal system of coordinate functions $\left\{\varphi_{k}\right\}_{k=1}^{\infty}$ satisfying the boundary conditions (10), consider the operator $T \varphi \equiv-\varphi^{\prime \prime}$. Furthermore, the function $\varphi$ must satisfy (10). It is not difficult to show that $T$ is a selfadjoint operator whose eigenvalues $\left\{\lambda_{k}\right\}_{k=1}^{\infty}$ are the roots of the transcendental equation

$$
\begin{gathered}
{[\sin \alpha \sin (\sqrt{\lambda} a)+\sqrt{\lambda} \cos \alpha \cos (\sqrt{\lambda} a)][\sin \gamma \cos (\sqrt{\lambda} b)-\sqrt{\lambda} \cos \gamma \sin (\sqrt{\lambda} b)]+} \\
+[\sqrt{\lambda} \cos \alpha \sin (\sqrt{\lambda} a)-\sin \alpha \cos (\sqrt{\lambda} a)][\sin \gamma \sin (\sqrt{\lambda} b)+\sqrt{\lambda} \cos \gamma \cos (\sqrt{\lambda} b)]=0 .
\end{gathered}
$$


The corresponding eigenfunctions $\varphi_{k}$ of $T$ are

$$
\begin{aligned}
& \varphi_{k}(s)=C_{k}\left\{\left[\sin \alpha \sin \left(\sqrt{\lambda_{k}} a\right)+\sqrt{\lambda_{k}} \cos \alpha \cos \left(\sqrt{\lambda_{k}} a\right)\right] \cos \left(\sqrt{\lambda_{k}} s\right)+\right. \\
& \left.+\left[\sqrt{\mu_{k}} \cos \alpha \sin \left(\sqrt{\lambda_{k}} a\right)-\sin \alpha \cos \left(\sqrt{\lambda_{k}} a\right)\right] \sin \left(\sqrt{\lambda_{k}} s\right)\right\}, \quad k=\overline{1, \infty} .
\end{aligned}
$$

We can determine the constants $C_{k}$ from the normalization condition.

Let us compare the results calculating the eigenvalues $\widetilde{\mu}_{k}(n)$ of the Sturm - Liouville spectral problem (10) using (5) and the Galerkin method. Enumerate the eigenvalues found in the ascending order.

Table 1 presents an example of calculating the eigenvalues of (10) for $a=1, b=3, \alpha=\pi / 5$, $\gamma=\pi / 7$, and $p(s)=s^{2}-10 s+11+\left(3 s^{2}-10 s+9\right) i$. We made the calculations on assuming that $\widetilde{\mu}_{k}(n)-\widetilde{\mu}_{k}(n-1)=0$ for $k=\overline{1,51}$ and $n=51$.

Table 1

\begin{tabular}{|c|c|c|c|}
\hline$k$ & $\widetilde{\mu}_{k}(51)$ & $\widehat{\mu}_{k}(51)$ & $\left|\widetilde{\mu}_{k}(51)-\widehat{\mu}_{k}(51)\right|$ \\
\hline 1 & $-3,745674+2,940862 i$ & $-4,310179+3,541650 i$ & 0,824365 \\
2 & $4,637443+2,247669 i$ & $4,802715+1,985491 i$ & 0,310043 \\
3 & $17,153279+2,110610 i$ & $17,260760+2,002740 i$ & 0,152264 \\
4 & $34,487259+2,062302 i$ & $34,553462+2,006407 i$ & 0,086644 \\
$\ldots$ & $\ldots$ & $\ldots$ & $\ldots$ \\
12 & $350,385311+2,006931 i$ & $350,392348+2,001575 i$ & 0,008844 \\
13 & $412,071642+2,005906 i$ & $412,077633+2,001356 i$ & 0,007523 \\
14 & $478,692507+2,005093 i$ & $478,679670+2,001177 i$ & 0,006480 \\
15 & $550,247973+2,004436 i$ & $550,252465+2,001032 i$ & 0,005639 \\
$\ldots$ & $\ldots$ & $\ldots$ & $\ldots$ \\
31 & $2366,259503+2,001039 i$ & $2366,260553+2,000234 i$ & 0,001314 \\
32 & $2521,705853+2,000975 i$ & $2521,706839+2,000234 i$ & 0,001233 \\
33 & $2682,086999+2,000917 i$ & $2682,087925+2,000220 i$ & 0,001159 \\
34 & $2847,402940+2,000815 i$ & $2847,403813+2,000208 i$ & 0,001092 \\
$\ldots$ & $\ldots$ & $\ldots$ & $\ldots$ \\
48 & $5679,979950+2,000433 i$ & $5679,980371+2,000116 i$ & 0,000527 \\
49 & $5919,317870+2,000416 i$ & $5919,318364+2,000043 i$ & 0,000062 \\
50 & $6162,590609+2,000399 i$ & $6163,590374+2,000449 i$ & 0,000253 \\
51 & $6412,798139+2,000384 i$ & $6412,818701+1,985049 i$ & 0,025650 \\
\hline
\end{tabular}

It is clear from Table 1 that as the index $k$ of the eigenvalue grows, the corresponding quantities $\left|\widetilde{\mu}_{k}(n)-\widehat{\mu}_{k}(n)\right|$ decrease, with the exception of the last two rows for $k=50$ and $k=51$.

Numerous calculations for various values of the parameters $a, b, c, d, \alpha, \beta$, and $p(s)$ demonstrated high accuracy and computational efficiency of our formula (5) for the eigenvalues of the spectral problem (10).

Table 2 presents the results of calculations of approximate values $\widetilde{p}\left(s_{k}\right)$ of the function $p(s)$ at the nodes $\left\{s_{k}\right\}_{k=1}^{21}$ for the parameter values $a=1, d=2, \alpha=\pi / 3, \gamma=\pi / 5$, and $\widetilde{f}\left(x_{k}\right)=\widetilde{\mu}_{k}-\lambda_{k}$ for $k=\overline{1,21}$, and the pertirbing operator $p(s)=s^{2}-3 s+16+\left(5 s^{2}-7 s+3\right) i$. Numerous calculations demonstrated that we can find the approximate values $\widetilde{p}\left(s_{k}\right)$ of the potential $p(s)$ at the nodes $\left\{s_{k}\right\}_{k=1}^{n}$ with the prescribed accuracy of residuals $\|A \widetilde{p}-\widetilde{f}\|$ in a large range of parameters and functional dependencies of the potential $p(s)$ of (10). The quantity

$$
\zeta_{k}=\left|\widetilde{f}\left(x_{k}\right)-\int_{a}^{b} K\left(x_{k}, s\right) \widetilde{p}(s) d s\right|
$$




\begin{tabular}{|c|c|c|c|}
\hline$k$ & $s_{k}$ & $\widetilde{p}\left(s_{k}\right)$ & $\zeta\left(s_{k}\right)$ \\
\hline 1 & 1,00 & $14.000005+0,992328 i$ & 0,007672 \\
2 & 1,05 & $13,952503+1,157641 i$ & 0,004859 \\
3 & 1,10 & $13,910002+1,347527 i$ & 0,002473 \\
4 & 1,15 & $13,872501+1,561034 i$ & 0,001465 \\
5 & 1,20 & $13,840001+1,799400 i$ & 0,000600 \\
6 & 1,25 & $13,812500+2,062430 i$ & 0,000070 \\
7 & 1,30 & $13,790000+2,350377 i$ & 0,000377 \\
8 & 1,35 & $13,772500+2,663136 i$ & 0,000636 \\
9 & 1,40 & $13,759999+3,000840 i$ & 0,000840 \\
10 & 1,45 & $13,752499+3,363440 i$ & 0,000939 \\
11 & 1,50 & $13,749999+3,750999 i$ & 0,000998 \\
12 & 1,55 & $13,752499+4,163517 i$ & 0,001079 \\
13 & 1,60 & $13,759999+4,600995 i$ & 0,000995 \\
14 & 1,65 & $13,772499+5,063481 i$ & 0,000912 \\
15 & 1,70 & $13,789999+5,550912 i$ & 0,000912 \\
16 & 1,75 & $13,812499+6,063392 i$ & 0,000892 \\
17 & 1,80 & $13,839999+6,600788 i$ & 0,000788 \\
18 & 1,85 & $13,872499+7,163296 i$ & 0,000796 \\
19 & 1,90 & $13,910000+7,750670 i$ & 0,000670 \\
20 & 1,95 & $13,952499+8,363875 i$ & 0,001379 \\
21 & 2,00 & $13,999999+0,001691 i$ & 0,001691 \\
\hline
\end{tabular}

determines the pointwise absolute error of the solution. The residual found at the node $s_{k}$ of the approximate solution $\widetilde{p}\left(s_{k}\right)$ equals $\|A \widetilde{p}-\widetilde{f}\|=9,54888210^{-17}$. In the numerical solution of the Fredholm integral equation of the first kind (9) by Tikhonov's regularization method we calculated the regularization parameter $\alpha$ using the method of residuals. In our case $\alpha=1,31490010^{-11}$.

The values $\zeta_{k}$ and $\|A \widetilde{p}-\widetilde{f}\|$ of pointwise absolute error and residual enable us to conclude that we find the approximate values $\widetilde{p}\left(s_{k}\right)$ of the function $p(s)$ at the discretization nodes $\left\{s_{k}\right\}_{k=1}^{21}$ with good accuracy.

\section{Conclusion}

Basing on the Galerkin method, we have developed a computationally efficient numerical method for solving the inverse spectral problems generated by perturbed selfadjoint operators given their spectrum alone. In comparison with the method based on the theory of regular traces, we remove the restriction on the perturbing operator $P$ of the form $\|P\|<0,5\left|\lambda_{n+\nu_{n}}-\lambda_{n}\right|$ for all $n \in N$. We wrote a MAPLE package enabling us to recover the potential $p(s)$ from the spectrum of the operator $L$.

\section{References}

1. Ambarzumian V.A. Ueber eine frage der eigengwerttheorie. Zeits. f. phisik, 1929, no. 53, pp. 690-665.

2. Borg G. Eine umkehrung der Sturm-Liouvilleschen eigenwertaufgabe. Acta Math., 1945, vol. 78 , no. 3 , pp. $1-90$. 
3. Marchenko V.A. Some Questions in the Theory of a Second Order Differential Operator. Soviet Mathematics, 1950, vol. 72, no. 3, pp. 457-460. (in Russian)

4. Krein M.G. Determination of the Density of an Inhomogeneous Symmetric String from its Frequency Spectrum. Soviet Mathematics, 1951, vol. 76, no. 3, pp. 345-348. (in Russian)

5. Sadovnichii V.A., Dubrovskii V.V. [Some Properties of Operators with Discrete Spectrum]. Differential Equations, 1979. vol. 15, no. 7, pp. 1206-1211. (in Russian)

6. Dubrovskii V.V., Nagorny A.V. [An Inverse Problem for the Laplace Operator with a Continuous Potential]. Differential Equations, 1990, vol. 26, no. 9, pp. 1563-1567. (in Russian)

7. Dubrovskii V.V., Nagorny A.V. [The Inverse Problem for the Degree of the Laplace Operator with Potential in $L^{2}$ ]. Differential Equations, 1992, vol. 28, no. 9, pp. 1552-1561. (in Russian)

8. Dubrovskii V.V. Reconstruction of a Potential from the Eigenvalues of Various Problems. Russian Mathematical Surveys, 1996, vol. 51, no. 4, pp. 732-733. DOI:10.1070/RM1996v051n04ABEH002978

9. Dubrovskii V.V. An Existence Theorem in the Inverse Problem of Spectral Analysis. Differential Equations, 1997, vol. 33, no. 12, pp. 1707-1709.

10. Dubrovskii V.V., Dubrovskii V.V. (Jr.) On the Existence Theorem for Solutions to the Inverse Problem of Spectral Analysis. Russian Mathematical Surveys, 2001, vol. 56, no. 1, pp. $154-155$. DOI: $10.4213 / \mathrm{rm} 364$

11. Zakirova G.A. An Inverse Problem for the Laplace Operator in the Isosceles Rectangular Triangle. Vestnik of Samara State University. Natural Science Series, 2008, no. 2, pp. 34-42. (in Russian)

12. Zakirova G.A. An Inverse Spectral Problem for Laplace Operator and It's Approximate Solution. Bulletin of the South Ural State University. Series: Mathematical Modelling, Programming and Computer Software, 2008, no. 27 (127), issue 2, pp. 19-27. (in Russian)

13. Sadovnichii V.A., Dubrovskii V.V., Dubrovskii V.V. (Jr.) The Inverse Problem of Spectral Analysis for the Degree of the Laplace Operator with Potential on the Rectangle. Doklady Mathematics, 2001, vol. 377, no. 3, pp. 310-312. (in Russian)

14. Sadovnichii V.A., Dubrovskii V.V., Dubrovskii V.V. (Jr.), Puzankova E.A. About Restoration the Potential in the Inverse Problem of Spectral Analysis. Doklady Mathematics, 2001, vol. 380 , no. 4, pp. 462-464. (in Russian)

15. Sadovnichii V.A., Dubrovskij V.V., Smirnova L.V. [The Uniqueness of the Solution of Inverse Problems of Spectral Analysis]. Doklady Mathematics, 2000, vol. 370, no. 3, pp. 319-321. (in Russian)

16. Sadovnichii V.A., Dubrovskij V.V., Puzankova E.A. [On the Inverse Problem of Spectral Analysis for the Powers of the Laplace Operator with Potential]. Doklady Mathematics, 1999, vol. 367, no. 3, pp. 307-309. (in Russian)

17. Sadovnichii V.A., Dubrovskij V.V., Puzankova E.A. [The Inverse Problem of Spectral Analysis for the Degree of the Laplace Operator on a Rectangle]. Differential Equations, 2000, vol. 36, no. 12, pp. 1693-1698. (in Russian)

18. Sedov A.I. About the Approximate Solution of the Inverse Problem of Spectral Analysis for Laplace Operator. Bulletin of the South Ural State University. Series: Mathematical Modelling, Programming and Computer Software, 2010, no. 16(192), issue 5, pp. 73-78.

19. Kadchenko S.I. Numerical Method for the Solution of Inverse Problems Generated by Perturbations of Self-Adjoint Operators by Method of Regularized Traces. Vestnik of Samara State University. Natural Science Series, 2013, no. 6 (107), pp. 23-30. (in Russian) 
20. Kadchenko S.I. A Numerical Method for Solving Inverse Problems Generated by the Perturbed Self-Adjoint Operators. Bulletin of the South Ural State University. Series: Mathematical Modelling, Programming and Computer Software, 2013. vol. 6, no. 4, pp. 15-25. (in Russian)

21. Kadchenko S.I. [Solution of Inverse Spectral Problems Generated by the Perturbed SelfAdjoint Operators by Method of Regularized Traces]. Bulletin of the Magnitogorsk State University. Mathematics, 2013, issue 15, pp. 34-43. (in Russian)

22. Kadchenko S.I. Numerical Method for Solving Inverse Spectral Problems Generated by Perturbed Self-Adjoint Operators. Vestnik of Samara State University. Natural Science Series, 2013, no. 9 (100), pp. 5-11.(in Russian)

23. Mihlin S.G. Variacionnye metody $v$ matematicheskoj fizike [Variational Methods in Mathematical Physics]. Moscow, Nauka, 1970. 510 p.

24. Demidovich B.P., Maron I.A. Osnovy vychislitel'noj matematiki [Fundamentals of Computational Mathematics]. Moscow, Nauka, 1966. 659 p.

25. Vasileva A.B., Tihonov N.A. Integralnye uravneniya [Integral Equations]. Moscow, MGU, 1989. $156 \mathrm{p}$.

Received February 9, 2015

УДК 519.642.8

DOI: $10.14529 / \mathrm{mmp} 150307$

\section{ЧИСЛЕННЫЙ МЕТОД РЕШЕНИЯ ОБРАТНЫХ СПЕКТРАЛЬНЫХ ЗАДАЧ}

\section{С.И. Кадченко, Г.А. Закирова}

На основе метода Галеркина разработан новый численный метод решения обратных спектральных задач, порожденных дискретными полуограниченными снизу операторами. В отличии от метода решения обратных спектральных задач, основанного на теории регуляризованных следов дискретных полуограниченными снизу операторов, в разработанном методе ослаблены ограничения на возмущающий оператор. Получено интегральное уравнение Фредгольма первого рода, позволяющее восстанавливать значения возмущающего оператора в узловых точках дискретизации области исследования. Метод был апробирован на спектральных задачах для оператора ШтурмаЛиувилля. Результаты многочисленных расчетов показали вычислительную эффективность метода.

Найдены простые формулы для вычисления собственных значений дискретных полуограниченных снизу оператора, без нахождения корней соответствующего векового уравнения. Вычисление собственных значений этих операторов можно начинать с любого их номера независимо от того, известны ли собственные значения с предыдущими номерами. Можно вычислять собственные значения возмущенного самосопряженного оператора с большими номерами, когда применение метода Галеркина становится затруднительным.

Ключевые слова: обратная спектральная задача; дискретные и самосопряженные операторы; собственные числа, собственные функции; некорректно поставленные задачи. \& Computer Software (Bulletin SUSU MMCS), 2015, vol. 8, no. 3, pp. 116-126 


\section{Литература}

1. Ambarzumian, V.A. Ueber eine frage der eigengwerttheorie / V.A. Ambarzumian // Zeits. f. Phisik. - 1929. - № 53. - P. 690-665.

2. Borg, G. Eine umkehrung der Sturm-Liouvilleschen eigenwertaufgabe / G. Borg // Acta Math. - 1945. - V. 78, № 3. - P. 1-90.

3. Марченко, В.А. Некоторые вопросы теории дифференциального оператора второго порядка / В.А. Марченко // ДАН СССР. - 1950. - Т. 72, № 3.- С. 457-460.

4. Крейн, М.Г. Определение плотности неоднородной симметричной струны по спектру частот / М.Г. Крейн // ДАН СССР. - 1951. - Т. 76, № 3.- С. 345-348.

5. Садовничий, В.А. О некоторых свойствах операторов с дискретным спектром / В.А. Садовничий, В.В. Дубровский // Дифференциальные уравнения. - 1979. - Т. 15, № 7. C. $1206-1211$.

6. Дубровский, В.В. К обратной задаче для оператора Лапласа с непрерывным потенциалом / В.В. Дубровский, А.Н. Нагорный // Дифференциальные уравнения. - 1990. Т. 26, № 9. - С. 1563-1567.

7. Дубровский, В.В. Обратная задача для степени оператора Лапласа с потенциалом из $L^{2}$ / В.В. Дубровский, А.Н. Нагорный // Дифференциальные уравнения. - 1992. - Т. 28, № 9. - С. $1552-1561$.

8. Дубровский, В.В. Восстановление потенциала по собственным значениям различных задач / В.В. Дубровский // Успехи математических наук. - 1996. - Т. 51, вып. 4. C. $155-156$.

9. Дубровский, В.В. Теорема существования в обратной задачи спектрального анализа / В.В. Дубровский // Дифференц. уравн. - 1997. - Т. 33, № 12. - С. 1702-1703.

10. Дубровский, В.В. К теореме существования решения в обратной задаче спектрального анализа / В.В. Дубровский, В.В. Дубровский (мл.) // Успехи математических наук. 2001. - Т. 56, вып. 1. - С. 161-162.

11. Закирова, Г.А. Обратная задача спектрального анализа для степеней оператора Лапласа на равнобедренном прямоугольном треугольнике / Г.А. Закирова, А.И. Седов // Вестник СамГУ. Естественнонаучная серия. - 2008. - № 2. - С. 34-42.

12. Закирова, Г.А. Приближенное решение обратной спектральной задачи для оператора Лапласа / Г.А. Закирова, А.И. // Вестник ЮУрГУ. Серия: Математическое моделирование и программирование. - 2008. - № 27 (127), вып. 2. - С. 19-27.

13. Садовничий, В.А. Обратная задача спектрального анализа для степеней оператора Лапласа с потенциалом на прямоугольнике / В.А. Садовничий, В.В. Дубровский, В.В. Дубровский (мл.) // ДАН. - 2001. - Т. 337, № 3. - С. 310-312.

14. О восстановлении потенциала в обратной задаче спектрального анализа / В.А. Садовничий, В.В. Дубровский, В.В. Дубровский (мл.), Е.А. Пузанкова // ДАН. - 2001. - Т. 380, № 4 . - С. 462-464.

15. Садовничий, В.А. О единственности решения обратных задач спектрального анализа / В.А. Садовничий, В.В. Дубровский, Л.В. Смирнова // ДАН. - 2000. - Т. 370, № 3. C. $319-321$.

16. Садовничий, В.А. Об обратной задаче спектрального анализа для степеней оператора Лапласа с потенциалом / В.А. Садовничий, В.В. Дубровский, Е.А. Пузанкова // ДАН. 1999. - Т. 367, № 3. - С. 307-309. 
17. Садовничий, В.А. Обратная задача спектрального анализа для степени оператора Лапласа на прямоугольнике / В.А. Садовничий, В.В. Дубровский, Е.А. Пузанкова // Дифференциальные уравнения. - 2000. - Т. 36, № 12. - С. 1693-1698.

18. Седов, А.И. О приближенном решении обратной задачи спектрального анализа для степени оператора Лапласа на прямоугольнике / А.И. Седов // Вестник ЮУрГУ. Серия: Математическое моделирование и программирование. - 2010. - № 16 (192), вып. 5. C. $73-78$.

19. Кадченко, С.И. Численный метод решения обратных задач, порожденных возмущенными самосопряженными операторами, методом регуляризованных следов / С.И. Кадченко // Вестник СамГУ. Естественнонаучная серия. - 2013. - № 6 (107). - С. 23-30.

20. Кадченко, С.И. Численный метод решения обратных задач, порожденных возмущенными самосопряженными операторами / С.И. Кадченко // Вестник ЮУрГУ. Серия: Математическое моделирование и программирование. - 2013. - Т. 6, № 4. - С. 15-25.

21. Кадченко, С.И. Решение обратных спектральных задач, порожденных возмущенными самосопряженными операторами, методом регуляризованных следов / С.И. Кадченко // Вестник МаГУ. Серия: Математика. - 2013. - Вып. 15. - С. 34-43.

22. Кадченко, С.И. Численный метод решения обратных спектральных задач, порожденных возмущенными самосопряженными операторами / С.И. Кадченко // Вестник СамГУ. Естественнонаучная серия. - 2013. - № 9 (100). - С. 5-11.

23. Михлин, С.Г. Вариационные методы в математической физике / С.Г. Михлин. - М.: Наука, 1970. - 510 с.

24. Демидович, Б.П. Основы вычислительной математики / Б.П. Демидович, И.А. Марон.М.: Наука, 1966. -659 с.

25. Васильева, А.Б. Интегральные уравнения / А.Б. Васильева, Н.А. Тихонов. - М.: МГУ, 1989. - 156 c.

Сергей Иванович Кадченко, доктор физико-математических наук, профессор, кафедра «Прикладная математика и информатика», Магнитогорский государственный технический университет им. Г.И. Носова (г. Магнитогорск, Российская Федерация), kadchenko@masu.ru.

Галия Амрулловна Закирова, кандидат физико-математических наук, доцент, кафедра «Уравнения математической физики», Южно-Уральский государственный университет (г. Челябинск, Российская Федерация), zakirova81@masu.ru.

Поступила в редакиию 9 февраля 2015 г. 